\title{
Principles for the production and dissemination of recruitment material for three clinical trials of an online intervention
}

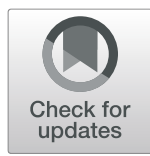

\author{
Stefan Rennick-Egglestone
}

\begin{abstract}
Some health research studies recruit participants through electronic mechanisms such as the placement of messages on social media platforms. This raises questions for ethics committee oversight, since effective social media campaigns might involve the production and dissemination of hundreds of contemporaneous messages. For the Narrative Experiences Online (NEON) study, we have developed nine principles to control the production and dissemination of promotional material. These have been approved by an ethics committee and enable the audit of our recruitment work. We propose that the drafting for approval of recruitment principles by health research studies may, in many cases, strike an appropriate balance between enabling ethical oversight of online recruitment work and the potential burden of message review.
\end{abstract}

Keywords: Participant recruitment, Online recruitment, Social media, Health research

\section{Main text}

Some health research studies recruit participants by disseminating recruitment material through electronic mechanisms. This material might include short messages disseminated in invitation emails or on social media platforms such as Facebook [1, 2]. It might also include more detailed study information distributed through websites such as clinicaltrials.gov [3]. In some cases, online dissemination of recruitment material can enable rapid recruitment of participants [4] and might also allow access to groups who are otherwise hard to reach [5]. It does of course risk excluding people who have difficulty accessing the Internet, perhaps for economic, cultural, social or personal reasons. This phenomenon has become known as "digital exclusion" [6].

Online dissemination of recruitment material raises some specific ethical issues. For example, interview

Correspondence: stefan.egglestone@nottingham.ac.uk

School of Health Sciences, Institute of Mental Health, University of Nottingham, Nottingham, UK evidence suggests that researchers who "lurk" on online health support forums to post recruitment messages can harm their capacity to act as a safe space for discussion $[7,8]$. Whilst social media recruitment campaigns might benefit from the production and dissemination of a large number of messages tailored to the interests of different groups [9], the review of the content of these messages by an ethics committee might be untenable at a scale that enables recruitment success. Although regulatory bodies typically specify clear approval processes for "traditional" recruitment media such as posters, we have found that approval processes can be ambiguous for online recruitment campaigns. This risks an unprincipled variation in the approaches that ethics committees are willing to approve. It also risks uncertainty about the approval status of recruitment messages.

The Narrative Experiences Online (NEON) study is currently (as of March 2020) conducting three clinical trials [10] of the NEON Intervention [11], an online mental health intervention designed to improve quality of life by providing access to a collection of mental

C C The Author(s). 2021 Open Access This article is licensed under a Creative Commons Attribution 4.0 International License, which permits use, sharing, adaptation, distribution and reproduction in any medium or format, as long as you give appropriate credit to the original author(s) and the source, provide a link to the Creative Commons licence, and indicate if changes were made. The images or other third party material in this article are included in the article's Creative Commons licence, unless indicated otherwise in a credit line to the material. If material is not included in the article's Creative Commons licence and your intended use is not permitted by statutory regulation or exceeds the permitted use, you will need to obtain permission directly from the copyright holder. To view a copy of this licence, visit http://creativecommons.org/licenses/by/4.0/ The Creative Commons Public Domain Dedication waiver (http://creativecommons.org/publicdomain/zero/1.0/) applies to the data made available in this article, unless otherwise stated in a credit line to the data. 
Table 1 Nine principles of recruitment material design selected for the NEON trials

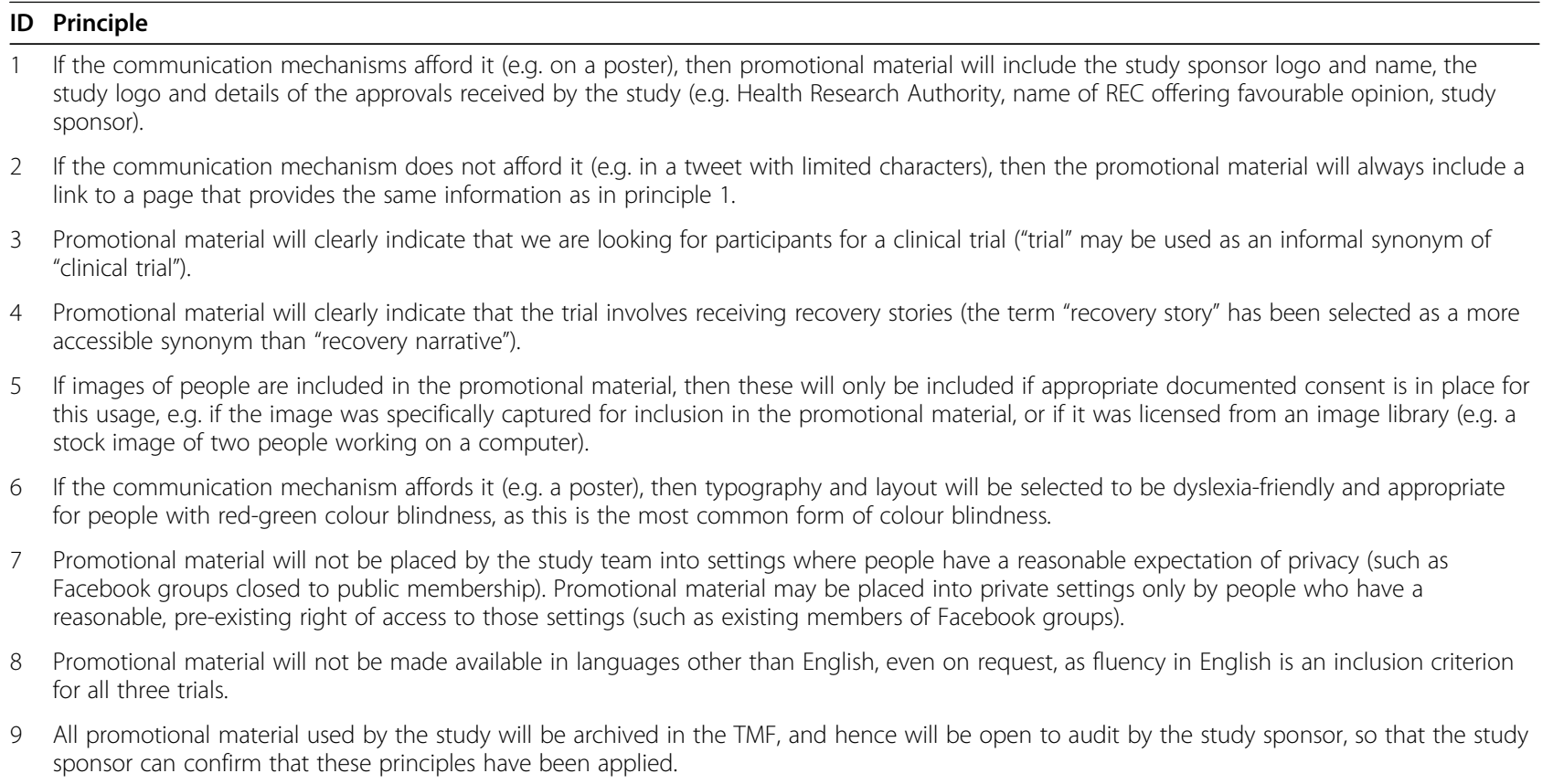

health recovery narratives [12]. All procedures for the NEON trials are conducted online, including the collection of consent, baseline and follow-up data [10]. In keeping with these online-only trial procedures, we have recruited at least $75 \%$ of our participants through online mechanisms, including through the placement of paid promotion on social media platforms and websites, and the distribution of electronic messages to more than 1000 community groups. All of our messaging has been constructed as part of targeted "campaigns", such as the "last push campaign" in which we constructed and disseminated messages indicating that limited spaces remained in our trials and the "diversity campaign" in which we worked with community champions to disseminate messages targeted at people who identify with non-majority demographic characteristics. The NEON trials have recruited to time and target. We believe that the incremental effort of posting large numbers of tailored messages has contributed towards this success, and will evaluate this in our process evaluation [10].

To allow for ethical oversight of our recruitment work, we developed 9 principles to control the production and dissemination of recruitment messages. These principles are referenced in our trial protocol [10] and were approved by an ethics committee in advance of our trials opening. They are presented in Table 1.

These principles were selected to serve the following purposes: ensuring that potential participants have access to appropriate and coherent trial information (principles 1-4 and 8), avoiding misuse of personal images (principle 5), encouraging inclusive design [13] (principle 6), precluding lurking for the purposes of recruitment (principle 7), and enabling an audit process for messaging (principle 9). These purposes were selected by the NEON research team as being the most important to address for our trials. Our experience of putting these principles into practice is that they have enabled rapid production and dissemination of recruitment messages and also enabled team discussion and knowledge development around ethical recruitment strategies.

We propose that this model-of agreeing specific principles for online recruitment work with ethical oversight bodies-is transferable to other health research studies and that it might be an appropriate solution for efficient use of online recruitment methods, whilst providing guarantees that online recruitment will be conducted ethically.

Whilst some principles might be common to a range of studies, researchers developing study approval applications might need to select a subset of principles that are most relevant to their population and study design. A community effort to identify and disseminate principles for online recruitment might support the production of ethically sound study approval applications. This approach as a whole might support studies in recruiting to time and target.

\section{Abbreviation}

NEON: Narrative Experiences Online 


\section{Supplementary Information}

The online version contains supplementary material available at https://doi. org/10.1186/s13063-021-05412-4.

Additional file 1. Recruitment principles for the NEON trials. Document presenting the nine principles controlling the design of recruitment material for the NEON trials.

\section{Acknowledgements}

Not applicable

\section{Author's contributions}

SRE drafted the recruitment principles referred to in this article and drafted this article. The author read and approved the final manuscript.

\section{Author's information}

At the time of submission, the author was the co-ordinator of the Narrative Experiences Online (NEON) study.

\section{Funding}

This article is independent research funded by the National Institute for Health Research (NIHR) under its Programme Grants for Applied Research Programme (Programme Grants for Applied Research, Personal experience as a recovery resource in psychosis: Narrative Experiences Online (NEON) Programme, RP-PG-0615-20016). The views expressed are those of the authors and not necessarily those of the NIHR or the Department of Health and Social Care.

\section{Availability of data and materials}

Not applicable.

\section{Declarations}

\section{Ethics approval and consent to participate}

Approval for the NEON trials was obtained from Leicester Central Research Ethics Committee, 19/EM/0326, including for the principles of promotional material described in this article.

\section{Consent for publication}

Not applicable.

\section{Competing interests}

The author declares that he has no competing interests.

Received: 23 March 2021 Accepted: 28 June 2021

Published online: 09 July 2021

\section{References}

1. Koo M, Skinner $\mathrm{H}$. Challenges of internet recruitment: a case study with disappointing results. J Med Internet Res. 2005;7(1):e6. https://doi.org/10.21 96/jmir.7.1.e6.

2. Whitaker C, Stevelink S, Fear N. The use of Facebook in recruiting participants for health research purposes: a systematic review. J Med Internet Res. 2017;19(8):e290. https://doi.org/10.2196/jmir.7071.

3. Riper H, Kramer J, Smit F, Conijn B, Schippers G, Cuijpers P. Web-based selfhelp for problem drinkers: a pragmatic randomized trial. Addiction. 2008; 103(2):218-27. https://doi.org/10.1111/j.1360-0443.2007.02063.x

4. Murray E, Khadjesari Z, White I, Kalaitzaki E, Godfrey C, McCambridge J, et al. Methodological challenges in online trials. J Med Internet Res. 2009;11(2):e9. https://doi.org/10.2196/jmir.1052.

5. Mathieu E, McGeechan K, Barratt A, Herbert R. Internet-based randomized controlled trials: a systematic review. J Am Med Inform Assoc. 2013;20(3): 568-76. https://doi.org/10.1136/amiajnl-2012-001175

6. Helsper EJ. A corresponding fields model for the links between social and digital exclusion. Commun Theory. 2012;22(4):403-26. https://doi.org/1 0.1111/j.1468-2885.2012.01416.x

7. Eysenbach $G$, Till JE. Ethical issues in qualitative research on internet communities. BMJ. 2001;323(7321):1103-5. https://doi.org/10.1136/bmj.323. 7321.1103.
8. King SA. Researching Internet communities: proposed ethical guidelines for the reporting of results. Inform Soc. 1996;12(2):119-28. https://doi.org/10.1 080/713856145

9. Freeman B, Potente $S$, Rock V, Mclver J. Social media campaigns that make a difference: what can public health learn from the corporate sector and other social change marketers. Public Health Res Pract. 2015;25(2):e2521517. https://doi.org/10.17061/phrp2521517.

10. Rennick-Egglestone S, Elliott R, Smuk M, Robinson C, Bailey S, Smith R, et al. Impact of receiving recorded mental health recovery narratives on quality of life in people experiencing psychosis, people experiencing other mental health problems and for informal carers: Narrative Experiences Online (NEON) study protocol for three randomised controlled trials. Trials. 2020; 21(1):1-34.

11. Slade M, Rennick Egglestone S, Llewellyn-Beardsley J, Yeo C, Roe J, Bailey S, et al. Recorded mental health recovery narratives as a resource for people affected by mental health problems: development of the Narrative Experiences Online (NEON) intervention. JMIR Format Res. 2021;5(5):e24417.

12. Llewellyn-Beardsley J, Rennick-Egglestone S, Callard F, Crawford P, Farkas M, Hui $A$, et al. Characteristics of mental health recovery narratives: systematic review and narrative synthesis. PLoS One. 2019;14(3):e0214678. https://doi. org/10.1371/journal.pone.0214678.

13. Clarkson PJ, Coleman R, Keates S, Lebbon C. Inclusive design: design for the whole population; 2013.

\section{Publisher's Note}

Springer Nature remains neutral with regard to jurisdictional claims in published maps and institutional affiliations.
Ready to submit your research? Choose BMC and benefit from:

- fast, convenient online submission

- thorough peer review by experienced researchers in your field

- rapid publication on acceptance

- support for research data, including large and complex data types

- gold Open Access which fosters wider collaboration and increased citations

- maximum visibility for your research: over $100 \mathrm{M}$ website views per year

At $\mathrm{BMC}$, research is always in progress.

Learn more biomedcentral.com/submission 